\title{
Ropivacaine and bupivacaine in obstetric analgesia
}

Studies comparing the efficacy of epidural analgesia for labour have been limited by lack of knowledge about the relative potencies of the involved agents, whether alone or in combination.

Recently a clinical model to determine the minimum local analgesic concentration has been developed [1]. This study design estimated the minimum local analgesic concentration or median effective concentration $\left(\mathrm{ED}_{50}\right)$ of any local anaesthetic using a relatively small number of subjects. This kind of study design uses the up-down sequential allocation technique with each subsequent patient's dose varied according to the previous patient's response. The design is more efficient at estimating $\mathrm{ED}_{50}$ than traditional dose-response designs because it focuses the testing of doses in the immediate vicinity of the $\mathrm{ED}_{50}$. In practice, the concentration of the local anaesthetic solution to be given to the patient is determined by the response of the previous patient to a higher or lower concentration using the up-down technique. The response must be binary, with the magnitude of the variable being tested varied in an up-down manner in subsequent tests. The median effective concentration $\left(\mathrm{EC}_{50}\right)$ can be estimated from the up-down sequences using a variety of techniques such as the Dixon and Massey method [2].

The minimum local analgesic concentration model allows the estimation of the median effective local analgesic concentration of epidurally administered local anaesthetics in the first stage of labour. Only with the use of equipotent analgesic concentrations can the relative local anaesthetic toxicity and motor effects of ropivacaine and bupivacaine be evaluated properly. Many studies have compared the local anaesthetic properties of epidurally administered ropivacaine and bupivacaine for analgesia in labour. Most investigators have compared ropivacaine $0.25 \%$ and bupivacaine $0.25 \%$ [3-6] and did not find significant differences in the quality of analgesia, sensory

Correspondence to: Giorgio Capogna, Department of Anaesthesia, Fatebenefratelli Hospital, Isola Tiberina, 38, I-00186 Rome, Italy. E-mail: g.capogna@ pronet.it

Accepted for publication February 2002 EJA 895 block or motor block. These studies highlighted the difficulty of demonstrating differences in potency when high concentrations at the top of the analgesic concentration-response curve [3-6] are studied. These concentrations correspond to the upper, flatter part of the dose-response curve where analgesic success is predictable.

In this issue of the European Journal of Anaesthesiology, Aşık and colleagues compare the effects of epidurally administered fentanyl combined with either bupivacaine $0.2 \%$ or ropivacaine $0.2 \%$ for the initiation and maintenance of analgesia during labour and delivery [7]. Their results suggest that epidural block using bupivacaine $0.2 \%$ or ropivacaine $0.2 \%$, combined with fentanyl, produces equivalent analgesia for pain relief during labour and delivery. They conclude that ropivacaine $0.2 \%$ combined with fentanyl $2 \mu \mathrm{g} \mathrm{mL}^{-1}$ provides effective analgesia with significantly less motor block and instrumental delivery than a bupivacaine-fentanyl combination at the same concentration. Again, these concentrations used are at the top of the analgesic concentration-response curve.

Studies of the minimum local analgesic concentration with respect to the relative analgesic potencies of ropivacaine and bupivacaine for epidural analgesia in labour have found ropivacaine to be $40 \%$ less potent than bupivacaine $[8,9]$. These results are in agreement with a study that compared the intrathecal administration of the two local anaesthetics [10]. Clearly, the analgesic effects as well as the effects on motor block of both bupivacaine and ropivacaine can only be properly evaluated when comparing equipotent doses.

Regardless of the choice of individual anaesthetic agent, motor blockade is related to the cumulative dose of the local anaesthetic agent. Furthermore, the argument about the motor block advantage of ropivacaine and its effect on the mode of delivery in this paper, as in almost all other papers, is incorrect because only the motor blockade of leg muscle groups was assessed. These have little or nothing to do with the power needed to expel the fetus.

The parturients studied by Aşı k and colleagues received $8 \mathrm{~mL}$ of the local anaesthetic solution and thus a low volume of a solution of relatively high 
concentration. However, there is clinical evidence that increasing the volume of the local anaesthetic to around $15-20 \mathrm{~mL}$ may be more efficient than increasing the concentration [11].

Opioids may be used in a dose-sparing capacity with local anaesthetic to reduce the dose needed, such that concomitant administration enables adequate analgesia with a concentration of local anaesthetic that would otherwise be sub-therapeutic. The development of low-dose regimens has shown that adequate analgesia may be maintained with a significantly reduced dose of anaesthetic if associated with a low dose of an opioid.

The majority of clinical experience is with bupivacaine and fentanyl [12]; this opioid also has a dosesparing effect on the requirements of ropivacaine [13]. Sufentanil has a similar dose-sparing action on both ropivacaine and bupivacaine $[14,15]$.

In Aşı k and colleagues' study, fentanyl has been added to a local anaesthetic that was given in a concentration effective on its own and for this reason no additional effects due to the opioid have been detected.

Another paper in this issue of the Journal by Pirbudak and colleagues [16] examines the efficacy of ropivacaine $0.05 \%$ and bupivacaine $0.05 \%$. The drugs were both combined with fentanyl $0.00015 \%$ to provide analgesia in labour. In this study, a bolus of bupivacaine $0.125 \% 10 \mathrm{~mL}$ plus fentanyl $50 \mu \mathrm{g}$, or ropivacaine $0.125 \% 10 \mathrm{~mL}$ plus fentanyl $50 \mu \mathrm{g}$, was administered via the epidural catheter to 40 nulliparous females. Then patient-controlled epidural analgesia was started with a basal infusion of bupivacaine $0.05 \% 10 \mathrm{~mL} \mathrm{~h}^{-1}$ plus fentanyl $1.5 \mu \mathrm{g} \mathrm{mL}^{-1}$, or ropivacaine $0.05 \%$ plus fentanyl $1.5 \mu \mathrm{g} \mathrm{mL}^{-1}$. It was concluded that both drugs produced similar effects, effective analgesia, together with high patient satisfaction and a high spontaneous delivery rate.

The two studies published in this issue are well conducted and designed, but their publication offers an opportunity to give careful consideration towards further studies. Yet again, the two local anaesthetics have not been compared in equipotent doses. In Aşı $\mathrm{k}$ and colleagues' study [7], the doses compared are high by today's standards and no effects of the addition of fentanyl have been observed due to this relatively high dose used. Also in Pirbudak and colleagues [16], no significant differences were observed between the two drugs, even if they were used at a lower concentration, but fentanyl was added in a dose effective on its own and may have masked the differences in analgesia due to the local anaesthetic solutions. Further research in obstetric analgesia should be directed to investigate doses, concentration, volumes and adjuvants that may be clinically useful, and comparisons between drugs should be made at equipotent doses or concentrations.

\author{
G. Capogna \\ Department of Anaesthesia \\ Fatebenefratelli Hospital \\ Rome, Italy
}

\section{References}

1. Columb MO, Lyons G. Determination of the minimum local analgesic concentrations of epidural bupivacaine and lidocaine in labor. Anesth Analg 1995; 81: 833-837.

2. Dixon WJ, Massey FJ. Introduction to Statistical Analysis, 4th edn. New York, USA: McGraw-Hill, 1983: 428-439.

3. Stienstra R, Jonker TA, Bourdrez P, et al. Ropivacaine $0.25 \%$ versus bupivacaine $0.25 \%$ for continuous epidural analgesia in labor: a double-blind comparison. Anesth Analg 1995; 80: 285-289.

4. Eddleston JM, Holland JJ, Griffin RP, et al. A doubleblind comparison of $0.25 \%$ ropivacaine and $0.25 \%$ bupivacaine for extradural analgesia in labour. Br J Anaesth 1996; 76: 66-71.

5. Muir HA, Writer D, Douglas J, et al. Double-blind comparison of epidural ropivacaine $0.25 \%$ and bupivacaine $0.25 \%$, for the relief of childbirth pain. Can J Anaesth 1997; 44: 599-604.

6. Owen MD, D’Angelo R, Gerancher JC, et al. $0.125 \%$ ropivacaine is similar to $0.125 \%$ bupivacaine for labor analgesia using patient-controlled epidural infusion. Anesth Analg 1998; 86: 527-531.

7. Aşık İ, Göktuğ A, Gülay I, Alkiş N, Uysalel A. Comparison of bupivacaine $0.2 \%$ and ropivacaine $0.2 \%$ combined with fentanyl for epidural analgesia during labour. Eur J Anaesthesiol 2002; 19: 263-270.

8. Capogna G, Celleno D, Fusco P, Lyons G, Columb M. Relative potencies of bupivacaine and ropivacaine for analgesia in labour. BrJ Anaesth 1999; 82: 371-373.

9. Polley LS, Columb MO, Naughton NN, Wagner DS, van de Ven CJM. Relative analgesic potencies of ropivacaine and bupivacaine for epidural analgesia in labor: implications for therapeutic indexes. Anesthesiology 1999; 90: 944-950.

10. McDonald SB, Liu SS, Kopacz DJ, Stephenson CA. Hyperbaric spinal ropivacaine: A comparison to bupivacaine in volunteers. Anesthesiology 1999; 90: 971-977.

11. Lyons G, Columb M, Gorton H. Minimum local analgesic volume for epidural bupivacaine $0.125 \% \mathrm{w} / \mathrm{v}$ in labour. BrJ Anaesth 1998; 80: 149-150.

12. Lyons G, Columb MO, Hawthorne $\mathrm{L}$, Dresner $\mathrm{M}$. Extradural pain relief in labour: Bupivacaine sparing by extradural fentanyl is dose dependent. Br J Anaesth 1997; 78: 493-497.

13. Ruban P, Sia ATH, Chong JL. The effect of adding fentanyl to ropivacaine $0.125 \%$ on patient-controlled epidural analgesia during labour. Anaesth Intensive Care 2000; 28: 517-521.

14. Polley LS, Columb MO, Wagner DS, Naughton NN. Dose dependent reduction of the minimum local analgesic 
concentration (MLAC) of bupivacaine by sufentanil for epidural analgesia in labor. Anesthesiology 1998; 89: 626-632.

15. Palm S, Gertzen W, Ledowski T, Gleim M, Wulf $\mathrm{H}$. Minimum local analgesic dose of plain ropivacaine versus ropivacaine combined with sufentanil during epidural analgesia for labour. Anaesthesia 2001; 56: 526-529.
16. Pirbudak L, Tuncer S, Koçoğlu H, Göksu S, Çelik Ç. Fentanyl added to bupivacaine $0.05 \%$ or ropivacaine $0.05 \%$ in patient-controlled epidural analgesia in labour. Eur J Anaesthesiol 2002; 19: 271-275. 